\title{
Effect of Mild Traumatic Brain Injury and Demographic Factors on Psychological Outcome
}

\author{
Elham Shafiei, ${ }^{1}$ Esmaeil Fakharian,,${ }^{1}$ Abdollah Omidi, ${ }^{2}$ Hossein Akbari, ${ }^{3}$ and Ali Delpisheh ${ }^{4}$ \\ ${ }^{1}$ Trauma Research Center, Kashan University of Medical Sciences, Kashan, IR Iran \\ ${ }^{2}$ Department of Clinical Psychology, Kashan University of Medical Sciences, Kashan, IR Iran \\ ${ }^{3}$ Department of Epidemiology and Biostatistics, School of Public Health, Kashan University of Medical Sciences, Kashan, IR Iran \\ ${ }^{4}$ Prevention of Psychosocial Injuries, Research Center, Ilam University of Medical Sciences, Ilam, IR Iran \\ "Corresponding author: Esmaeil Fakharian, Trauma Research Center, Kashan University of Medical Sciences, Kashan, IR Iran. Tel/Fax: +98-3615620634, E-mail: \\ efakharian@gmail.com
}

Received 2015 May 04; Revised 2016 January 30; Accepted 2016 January 30.

\begin{abstract}
Background: It is well-known that severe brain injury can make people susceptible to psychological symptoms. However, mild traumatic brain injury (MTBI) is still open for discussion.

Objectives: This study aimed to compare psychological symptoms of MTBI patients with those without MTBI considering demographic auxiliary variables.

Patients and Methods: This prospective cohort study was conducted on 50 MTBI patients and 50 healthy subjects aged 15 - 65 years. Psychological assessment was carried out six months post-injury using a series of self-report measures including the brief symptom inventory (BSI) scale. Other information of the individuals in the two groups was recorded prospectively. Data were analyzed using the chi-square test, t-test, and multiple linear regression tests.

Results: There was a significant difference between the MTBI patients and healthy subjects in all subscales and total score of BSI. Our findings showed that obsession-compulsion and anxiety subscales were significantly more common in the MTBI patients than in the healthy subjects. Also, multivariate regression analysis six months post-injury showed that head trauma and substance abuse can have an effect on psychological symptoms.

Conclusions: Mild traumatic brain injuries despite of the normal CT scan and history of substance abuse are closely related to psychological symptoms. Therefore, it is recommended that patients with brain trauma 6 months post-injury and subjects with a history of substance abuse be evaluated for psychological distress to support better rehabilitation.
\end{abstract}

Keywords: Mild Traumatic Brain Injury, Psychological Symptoms, Brief Symptom Inventory

\section{Background}

Mild traumatic brain injury (MTBI) is one of the most prevalent worldwide neurological conditions, which constitutes over $80 \%$ of all traumatic brain injuries $(1,2)$.

Although most of the TBI patients recover well, about $70 \%-90 \%$ of them complain of psychological and neurological symptoms often weeks or months after the original head trauma $(3,4)$. Neuropsychological literature has shown a direct correlation between TBI and obsessivecompulsive disorder (OCD), anxiety (5) and other psychological problems including irritability, apathy or depression (6-8). This problem may affect every aspect of an individual's life, social and family relationships (9), potential employment opportunities, emotional health and even education (10-14). Traumatic brain injuries (TBIs) and especially mild ones (MTBIs) have been less commonly studied for their psychiatric consequences. Rezaei et al. (15) reported that four months after a brain injury, the TBI sever- ity was more evident in patients who had developed mental disorders compared to those without mental disorders. Finset et al. (16) have also revealed psychological distress even three years after injury. On the other hand, one of the biggest encountered challenges is to understand the duration of recovery from injury (from the onset of the injury until the complete recovery) which can be effective in the development of psychological symptoms and timely identification of this duration can play a significant role in the recovery process.

\section{Objectives}

The aim of this study was to compare psychological symptoms in patients with and without MTBI using the brief symptom inventory (BSI) instrument 6 months post injury. Furthermore, the effect of MTBI on psychological symptoms, and demographic characteristics of the patients were also examined. 


\section{Patients and Methods}

\subsection{Patients and Control Samples}

Fifty victims of MTBI with the Glasgow coma scale (GCS) between 13 and 15 in the age range of 15 to 65 years and any sex with any radiographic or CT scan findings were selected as the exposure group. Fifty healthy people with no history of head trauma in the past 6 months as the unexposed group usually from those referred to hospital to accompany the injured person were randomly enrolled in the study. These were matched in sex and education level with the injured cases. It was a group matching process. Considering the prevalence of $2 \%$ of mental disorders in healthy subjects and $43 \%$ in patients with moderate trauma and also the confidence interval of $95 \%$ and test power of $90 \%$, 51 persons were calculated to be required for each study group (17). The study was approved by the hospital ethics committee, and informed consent was obtained from all cases.

\subsection{Exclusion Criteria}

Individuals younger than 15 or older than 65 years with any evidence of spinal cord injury, previous nervous system disease, such as brain tumors, those with surgery and cerebrovascular accidents, patients in vegetative state, or with communication problems and psychotic diseases as well as patients with mental retardation, previous history of head trauma and those who were not willing to contribute to the study were excluded.

\subsection{Instruments}

a, Demographic questionnaire included age, sex, and education, habits and also information such as smoking, alcohol consumption and underlying diseases of the individuals in the two groups was recorded prospectively; b, neurologic and pathologic questionnaire included the GCS score at the time of admission and findings on X-ray and brain CT scan including fracture and any focal or diffuse brain injuries; $c$, the third questionnaire was for the assessment of the cognitive complaints including the self-report 53 item. The BSI is the short version of the SCL-90-R (18), and is a brief screen of psychologic distress with a GSI and 9 clinical subscales. This instrument has been employed and tested in various cultural and a screening tool for psychological disturbance (19). The measure has been shown to be reliable and valid in MTBI. Internal consistency was determined by Cronbach's alpha coefficient and estimated to be 0.86 (20) in another study in Iran (21). Those with GSI or at least two BSI subscales $\geq 63$ were identified as patients with mental disorder (22). The symptom level of each item of the BSI is rated on a 5-point scale of distress from 0 (not at all) to 4 (extremely). The average of the scores of these 53 items, called as the GSI indicates an overall degree of mental distress. The items of the BSI are known to factories as nine primary symptoms such as compulsive (OCD), depression (DEP), anxiety (ANX), hostility (HOS), phobic anxiety (PHO), paranoid ideation (PAR), and psychoticism (PSY) comprising in all 53 items.

\subsection{Procedure}

At first, each patient was referred to a neurosurgeon for neurological evaluations. If the patient had met the inclusion criteria, a demographic questionnaire was then employed to record information such as age, gender, education level, and GCS. Participation in our study was voluntary with given written informed consent. For the 6 months follow-up, the patients were invited by the trauma research center in Shahid Beheshti hospital, Kashan, Iran, via phone calls for psychological assessments by a clinical psychologist. If the individuals were illiterate, a psychologist would help him/her completing the questionnaire. The information obtained from the neurological evaluation, organic brain pathology, and psychological assessments were blinded to the psychologist to reduce any nonblinded outcome assessment bias or diagnostic suspicion bias. Also, we recruited 50 healthy subjects during a period of 6 months, all matched for sex and education. If there was missing of the follow-up, phone calls were repeated two times with 2 weeks interval. To persuade the cases, they were told that they are examined by the neurosurgeon for free.

\subsection{Data Analysis}

For statistical analysis of the data, along with descriptive statistics, independent t-test was used to compare means between the two groups. To assure whether TBI affects psychological symptom, the stepwise multivariate linear regression model was used. All demographic data are brought in the linear regression model except sex and education level. The criteria of including variables $\alpha<$ 0.05 , also we used to adjusted R square for goodness of fit test. Since we focused on TBI variable, the demographic variables such as age, marital status, job, history of substance use, and history of alcohol use were considered as auxiliary variables. Statistical analyses were all performed using the SPSS software version 18.

\section{Results}

\subsection{Demographics}

Fifty subjects with MTB injury and 50 healthy subjects were enrolled in this study. Mean age for the entire sample 
was $35.4(\mathrm{SD}=12.9)$ years in which $80 \%$ were male. Also, the two groups were matched in terms of the education level and sex. Chi-square test showed no significant differences between the two groups in terms of demographic characteristics $(\mathrm{P}>0.05)$ (Table 1$)$.

Table 1. Comparison of Demographic Data for Traumatic Brain Injury Patients and Healthy Subjects ${ }^{\mathrm{a}}$

\begin{tabular}{|c|c|c|c|}
\hline $\begin{array}{l}\text { Socio- } \\
\text { Demographics }\end{array}$ & $\begin{array}{l}\text { MTBI patients, } \\
\text { (Exposed) }\end{array}$ & $\begin{array}{l}\text { Healthy Subjects, } \\
\text { (Unexposed) }\end{array}$ & P Value \\
\hline Age, $y$ & & & 0.69 \\
\hline$\leq 24$ & $16(32)$ & $15(30)$ & \\
\hline $25-34$ & $16(32)$ & $13(26)$ & \\
\hline$\geq 35$ & $18(36)$ & $22(44)$ & \\
\hline Residue & & & 0.33 \\
\hline Village & $9(18)$ & $13(26)$ & \\
\hline City & $41(82)$ & $37(74)$ & \\
\hline Marital Status & & & 0.82 \\
\hline Single & $13(26)$ & $14(28)$ & \\
\hline Married $^{\mathrm{b}}$ & $37(74)$ & $36(72)$ & \\
\hline Sex & & & 1.00 \\
\hline Male & $40(80)$ & $40(80)$ & \\
\hline Female & $10(20)$ & $10(20)$ & \\
\hline $\begin{array}{l}\text { Economic status } \\
\text { (average) }\end{array}$ & $42(84)$ & $43(86)$ & 0.259 \\
\hline Job (worker) & $22(44)$ & $20(40)$ & 0.178 \\
\hline $\begin{array}{l}\text { Family } \\
\text { psychiatric } \\
\text { history }\end{array}$ & $9(18)$ & $6(12)$ & 0.401 \\
\hline History of disease & $13(6)$ & $8(16)$ & 0.22 \\
\hline $\begin{array}{l}\text { History of use of } \\
\text { drug }\end{array}$ & $15(30)$ & $11(22)$ & 0.36 \\
\hline $\begin{array}{l}\text { History of use of } \\
\text { alcohol }\end{array}$ & - & $1(2)$ & 0.315 \\
\hline $\begin{array}{l}\text { History of } \\
\text { substance abuse }\end{array}$ & $7(14)$ & $5(10)$ & 0.538 \\
\hline $\begin{array}{l}\text { History of } \\
\text { anesthesia }\end{array}$ & $19(38)$ & $15(3)$ & 0.398 \\
\hline $\begin{array}{l}\text { History of } \\
\text { Hospitalization }\end{array}$ & $17(34)$ & $13(26)$ & 0.384 \\
\hline
\end{tabular}

${ }^{\mathrm{a}}$ Values are expressed as No. (\%).

${ }^{\mathrm{b}}$ Divorced and widowed people were considered as married people.

Posttraumatic amnesia was seen in 19 cases (38\%) of the MTBI victims. Other data about neurological condition of the patients are shown in Table 2.

As Table 3 shows the highest mean and standard deviation scores in TBI patients for OCD was $1.68 \pm 0.88$, while it was $0.95 \pm 0.36$ for the control subjects.

Afterwards, the mean \pm standard deviation (SD) of anx-
Table 2. Comparison of Neurological Data for Traumatic Brain Injury Patients ${ }^{\mathrm{a}}$

\begin{tabular}{|c|c|}
\hline Neurological Characteristics & TBI Patients \\
\hline \multicolumn{2}{|l|}{ PTA } \\
\hline Yes & $19(38)$ \\
\hline no & $31(62)$ \\
\hline Multiple trauma (yes) & $27(54)$ \\
\hline \multicolumn{2}{|l|}{ Type of associated injury } \\
\hline Upper limbs & $27(54)$ \\
\hline Lower limbs & $15(30)$ \\
\hline Thoracic injury & $8(6)$ \\
\hline \multicolumn{2}{|l|}{ Location of brain damage } \\
\hline Frontal lobe & $31(62)$ \\
\hline Temporal lobe & $19(12)$ \\
\hline \multicolumn{2}{|l|}{ Duration of hospitalization } \\
\hline 1-3 days & $21(42)$ \\
\hline 4 - 5 days & $25(50)$ \\
\hline 1 week & $4(8)$ \\
\hline
\end{tabular}

${ }^{\mathrm{a}}$ Values are expressed as No. (\%).

iety was $1.58 \pm 0.89$ in the TBI patients, while it was $0.79 \pm$ 0.39 for the control subjects.

The results of the t-test showed that there were statistical differences between the two groups in OCD and other subscales of the BSI $(\mathrm{P}<0.001)$ (Table 3$)$.

On the basis of a screening questionnaire and supposing $\mathrm{T} \geq 60,21$ cases $(42 \%)$ of the MTBI group and $1(2 \%)$ of the unexposed group were suspected to OCD. The chi-square test results showed a significant association between the two groups and positive cases in each of the subscales $(\mathrm{P}<$ 0.001). Also, in other subscales, the association was significant $(\mathrm{P}<0.001)$ (Table 4$)$.

\subsection{Predictors of Psychological Distress}

The results of the stepwise multiple linear regression model showed that the entire included variables were significantly effective in the groups $(\mathrm{P}<0.001)$. In addition, a history of substance abuse $(\mathrm{P}=0.047)$ has been influenced by the BSI score.

The R square and adjusted R square of the model was 0.431 and 0.413 , respectively, which stated that the model was well fitting for the data. Also, analysis of variance for goodness of fitness of the test confirmed this result $(\mathrm{F}=$ 24.775, $\mathrm{P}<0.001)$ 
Table 3. Comparison of General Severity Index and Nine Scales of Brief Symptom Inventory Between Traumatic Brain Injury Patients and Unexposed Subjects ${ }^{\mathrm{a}}$

\begin{tabular}{lccc}
\hline BSI Dimensions & $\begin{array}{c}\text { TBI Patients, } \\
\text { (Exposed) }\end{array}$ & $\begin{array}{c}\text { Control Subjects, } \\
\text { (Unexposed) }\end{array}$ & P Value \\
\hline HOS (hostility) & $1.44 \pm 0.78$ & $0.74 \pm 0.39$ & $<0.001$ \\
\hline DEP(depression) & $1.57 \pm 0.70$ & $0.83 \pm 0.44$ & $<0.001$ \\
\hline ANX (anxiety) & $1.58 \pm 0.89$ & $0.79 \pm 0.39$ & $<0.001$ \\
\hline $\begin{array}{l}\text { PSY } \\
\text { (psychoticism) }\end{array}$ & $1.47 \pm 0.65$ & $0.90 \pm 0.45$ & $<0.001$ \\
\hline $\begin{array}{l}\text { OCD (obsessive- } \\
\text { compulsive) }\end{array}$ & $1.68 \pm 0.88$ & $0.95 \pm 0.36$ & $<0.001$ \\
\hline $\begin{array}{l}\text { SOM } \\
\text { (somatization) }\end{array}$ & $1.44 \pm 0.74$ & $0.81 \pm 0.43$ & $<0.001$ \\
\hline $\begin{array}{l}\text { PHO } \\
\text { (phobic-anxiety) }\end{array}$ & $1.46 \pm 0.76$ & $0.82 \pm 0.43$ & $<0.001$ \\
\hline $\begin{array}{l}\text { PAR(Paranoid- } \\
\text { Ideation) }\end{array}$ & $1.36 \pm 0.75$ & $0.90 \pm 0.45$ & $<0.001$ \\
\hline $\begin{array}{l}\text { IPS } \\
\text { (interpersonal } \\
\text { sensitivity) }\end{array}$ & $1.50 \pm 0.67$ & $0.93 \pm 0.40$ & $<0.001$ \\
\hline $\begin{array}{l}\text { GSI (global } \\
\text { severity index) }\end{array}$ & $1.52 \pm 0.54$ & $0.86 \pm 0.29$ & $<0.001$ \\
\hline Values & & & \\
\hline
\end{tabular}

${ }^{\mathrm{a}}$ Values are expressed as mean $\pm \mathrm{SD}$.

Table 4. Frequency of Psychological Disorders in All of the Subscales in the Exposed and Unexposed Groups $(\mathrm{n}=50)$

\begin{tabular}{lccc}
\hline BSI Dimensions & $\begin{array}{c}\text { Trauma Group, } \\
\text { (Exposed) }\end{array}$ & $\begin{array}{c}\text { Healthy Group, } \\
\text { (Unexposed) }\end{array}$ & PValue \\
\hline DEP(depression) & $17(34)$ & $1(2)$ & $<0.001$ \\
\hline $\begin{array}{l}\text { SOM } \\
\text { (somatization) }\end{array}$ & $16(32)$ & $1(2)$ & $<0.001$ \\
\hline $\begin{array}{l}\text { PSY } \\
\text { (psychoticism) }\end{array}$ & $14(28)$ & $3(6)$ & 0.003 \\
$\begin{array}{l}\text { ANX (anxiety) } \\
\text { OCD (obsessive- } \\
\text { compulsive) }\end{array}$ & $18(36)$ & $1(2)$ & $<0.001$ \\
\hline $\begin{array}{l}\text { IPS } \\
\text { (interpersonal } \\
\text { sensitivity) }\end{array}$ & $21(42)$ & $1(2)$ & $<0.001$ \\
\hline $\begin{array}{l}\text { PHO } \\
\text { (phobic-anxiety) }\end{array}$ & $20(40)$ & $1(2)$ & $<0.001$ \\
\hline $\begin{array}{l}\text { HOS (hostility) } \\
\text { PAR(Paranoid- }\end{array}$ & $18(36)$ & $1(2)$ & $<0.001$ \\
Ideation) & $10(20)$ & $1(2)$ & $<0.001$ \\
\hline $\begin{array}{l}\text { GSI (global } \\
\text { severity index) }\end{array}$ & $11(22)$ & $1(2)$ & 0.004 \\
\hline
\end{tabular}

\section{Discussion}

In this study, psychological symptoms of trauma patients were compared with the control group using the BSI instrument 6 months post injury. Moreover, the effect of demographic auxiliary variables on these symptoms was examined.

Our findings showed statistical differences between the two groups in all subscales of the BSI. The mean total score (GSI) in MTBI was $1.52 \pm 0.54$, whereas it was $0.86 \pm$ 0.29 in the control group. However, on the basis of the BSI score, the mean GSI in the TBI patients was higher than in the control group six months post injury. This implies that TBI despite normal CT scan and high levels of consciousness (GCS scores between 13 and 14) is effective on psychological function of the patients. This is compatible with Yeates et al. (23), and Sojka et al. (24) studies in which $10 \%$ of the patients had 3 or more posttraumatic stress-related symptoms 1 year after MTBI. Lin et al. (25), also, in their longitudinal study over a year after brain damage noticed significant changes in the emotional quality of life for patients.

The highest mean and standard deviation scores in TBI patients in this study were related to OCD and anxiety subscales, which this result was also found in studies (26-31) during the first year after TBI.

Linear regression analysis was used to determine the factors that contribute to psychological symptoms six months post-injury. In all steps of the regression analysis, such demographic characteristics as preinjury history of head trauma, effect of groups and history of substance abuse were the strongest predictors of depressive symptoms. This is consistent with a study (32) indicating that history of head trauma and substance abuse can be correlated with psychological symptoms six months post injury. This is in contrast with findings of others (33-38), which showed no differences between TBI and mental health on demographic or injury factors. Also, six month follow-up of the MTBI patients showed a significant difference between patients with and without psychological symptoms and substance abuse indicating that psychological symptoms may occur as a result of life-style change following injury.

Considering the point that psychological symptoms are highly dependent to social and cultural backgrounds, very high number of head injury victims all around the world on the one hand, and the limited number of studies on the effect of MTBI on psychosocial status of the victims, on the other hand, for the MTBI patients with previous history of head trauma and substance abuse, evaluation and followed-up for psychological distress is recommended to support better rehabilitation of the patients. This may result in higher quality of life and better psychosocial function. 
Table 5. Analysis

\begin{tabular}{|c|c|c|c|c|c|}
\hline \multirow[t]{3}{*}{ Parameters } & \multicolumn{3}{|c|}{ Coefficients } & \multirow[t]{3}{*}{$\mathbf{t}$} & \multirow[t]{3}{*}{ P Value } \\
\hline & \multicolumn{2}{|c|}{ Unstandardized Coefficients } & \multirow{2}{*}{$\begin{array}{c}\text { Standardized Coefficients } \\
\text { Beta }\end{array}$} & & \\
\hline & B & Std. Error & & & \\
\hline Constant & 43.17 & 1.115 & & 38.7 & $\mathrm{P}<0.001$ \\
\hline Group & 11.425 & 1.552 & 0.573 & 7.35 & $\mathrm{P}<0.001$ \\
\hline
\end{tabular}

\subsection{Limitations of the Study}

Our study had some limitations. In this study, MTBI patients and unexposed were matched based on the sex and educational level. Therefore, the effect of these variables on traumatic patients' mental health has been studied and since the sex and education levels can also have a significant effect on mental health of the traumatic patients, further research is recommended to study the effect of these two variables clearly.

\subsection{Conclusions}

In conclusion, it can be stated that MTBIs just as the more severe events can result in psychological disturbances 6 months after TBI. Considering the fact that the MTBIs include the highest number of head injuries while they grossly appear normal, more specific attention to this aspect of their recovery in patients and even their families in longer follow up durations and more comprehensive research plans is recommended.

\section{Acknowledgments}

The authors dedicate their sincere thanks to all of the individuals contributing to the study.

\section{Footnotes}

Authors' Contribution: Elham Shafiei, Abdollah Omidi and Ali Delpisheh, drafting the manuscript; Hossein Akbari, analysis of data; Esmaeil Fakharian, supervisor and assistant in writing the paper.

Funding/Support: This article is a part of PhD dissertation supported by trauma research center of Kashan University of Medical Sciences (grant no: 92153).

\section{References}

1. Marin JR, Shofer FS, Chang I, Mills AM. Adherence to a clinical decision policy for head computed tomography in adult mild traumatic brain injury. Am J Emerg Med. 2015;33(2):299-300. doi: 10.1016/j.ajem.2014.11.017. [PubMed: 25481341].
2. Cassidy JD, Carroll LJ, Peloso PM, Borg J, von Holst H, Holm L, et al. Incidence, risk factors and prevention of mild traumatic brain injury: results of the WHO Collaborating Centre Task Force on Mild Traumatic Brain Injury. J Rehabil Med. 2004(43 Suppl):28-60. [PubMed: 15083870].

3. Gould KR, Ponsford JL, Johnston L, Schonberger M. Relationship between psychiatric disorders and 1-year psychosocial outcome following traumatic brain injury. J Head Trauma Rehabil. 2011;26(1):79-89. doi: 10.1097/HTR.ob013e3182036799. [PubMed: 21209565].

4. Hajek CA, Yeates KO, Gerry Taylor H, Bangert B, Dietrich A, Nuss KE, et al. Relationships among post-concussive symptoms and symptoms of PTSD in children following mild traumatic brain injury. Brain Inj. 2010;24(2):100-9. doi: 10.3109/02699050903508226. [PubMed: 20085447].

5. Schonberger M, Ponsford J, Gould KR, Johnston L. The temporal relationship between depression, anxiety, and functional status after traumatic brain injury: a cross-lagged analysis. J Int Neuropsychol Soc. 2011;17(5):781-7. doi: 10.1017/S1355617711000701. [PubMed: 21729404].

6. Alway Y, McKay A, Ponsford J, Schonberger M. Expressed emotion and its relationship to anxiety and depression after traumatic brain injury. Neuropsychol Rehabil. 2012;22(3):374-90. doi: 10.1080/09602011.2011.648757. [PubMed: 22292905].

7. Chaves C, Trzesniak C, Derenusson GN, Araujo D, Wichert-Ana L, Machado-de-Sousa JP, et al. Late-onset social anxiety disorder following traumatic brain injury. Brain Inj. 2012;26(6):882-6. doi: 10.3109/02699052.2012.666373. [PubMed: 22583179].

8. Donnell AJ, Kim MS, Silva MA, Vanderploeg RD. Incidence of postconcussion symptoms in psychiatric diagnostic groups, mild traumatic brain injury, and comorbid conditions. Clin Neuropsychol. 2012;26(7):1092-101. doi: 10.1080/13854046.2012.713984. [PubMed: 22935025].

9. Yeates KO, Taylor HG, Walz NC, Stancin T, Wade SL. The family environment as a moderator of psychosocial outcomes following traumatic brain injury in young children. Neuropsychology. 2010;24(3):345-56. doi: 10.1037/a0018387. [PubMed: 20438212].

10. Yeates KO, Taylor HG, Woodrome SE, Wade S, Stancin T, Drotar D. Race as a moderator of parent and family outcomes following pediatric traumatic brain injury. Pediatr Psycho. 2002;27(4):393-403.

11. Garber BG, Rusu C, Zamorski MA. Deployment-related mild traumatic brain injury, mental health problems, and post-concussive symptoms in Canadian Armed Forces personnel. BMC Psychiatry. 2014;14:325. doi: 10.1186/s12888-014-0325-5. [PubMed: 25410348].

12. Titus DJ, Furones C, Atkins CM, Dietrich WD. Emergence of cognitive deficits after mild traumatic brain injury due to hyperthermia. Exp Neurol. 2015;263:254-62. doi: 10.1016/j.expneurol.2014.10.020. [PubMed: 25447938].

13. Scholten AC, Haagsma JA, Andriessen TMJC, Vos PE, Steyerberg EW, Van Beeck EF, et al. Health-related quality of life after mild, moderate and severe traumatic brain injury: Patterns and predictors of suboptimal functioning during the first year after injury. Injury. 2015;46(4):61624. 
14. Pickrell BB, Hollier LJ. Review of "Strategies for Reducing Regional Variation in the Use of Surgery-A Systematic Review" by Reames BN, Shubeck SP, Birkmeyer JD in Annals of Surgery. 259: 616-627; 2014.J Craniofac Surg. 2014 doi: 10.1097/SCS.0000000000001095. [PubMed: 25340693].

15. Rezaei S, Salehi I, Moosavi H, Yousefzaeh S. Axis i psychopathology during the first four mounts after traumatic brain injury. Iranian J Psychiatr Clinic Psychol. 2012;18(1):13-28.

16. Finset A, Anke AW, Hofft E, Roaldsen KS, Pillgram-Larsen J, Stanghelle JK. Cognitive performance in multiple trauma patients 3 years after injury. Psychosom Med. 1999;61(4):576-83. [PubMed: 10443768].

17. Skandsen T, Finnanger TG, Andersson S, Lydersen S, Brunner JF, Vik A. Cognitive impairment 3 months after moderate and severe traumatic brain injury: a prospective follow-up study. Arch Phys Med Rehabil. 2010;91(12):1904-13. doi: 10.1016/j.apmr.2010.08.021. [PubMed: 21112433].

18. Urban R, Kun B, Farkas J, Paksi B, Kokonyei G, Unoka Z, et al. Bifactor structural model of symptom checklists: SCL-90-R and Brief Symptom Inventory (BSI) in a non-clinical community sample. Psychiatry Res. 2014;216(1):146-54. doi: 10.1016/j.psychres.2014.01.027. [PubMed: 24524946].

19. Baum G, Basen-Engquist K, Swartz MC, Parker PA, Carmack CL. Comparing PROMIS computer-adaptive tests to the Brief Symptom Inventory in patients with prostate cancer. Qual Life Res. 2014;23(7):2031-5. doi: 10.1007/s11136-014-0647-2. [PubMed: 24532436].

20. Fakharian E, Omidi A, Shafiei E, Nademi A. Mental health status of patients with mild traumatic brain injury admitted to shahid beheshti hospital of kashan, iran. Arch Trauma Res. 2015;4(1):ee17629. doi:10.5812/atr.17629. [PubMed: 25866741].

21. Mohammadkhani P, Dobson KS, Amiri M, Ghafari FH. Psychometric properties of the Brief Symptom Inventory in a sample of recovered Iranian depressed patients. Int J clinic health psychol. 2010;10(3):541-51.

22. Hessel A, Schumacher J, Geyer M, Brähler E. Symptom-Checkliste SCL90-R. Diagnostica. 2001;47(1):27-39. doi: 10.1026//0012-1924.47.1.27.

23. Yeates KO. Mild traumatic brain injury and postconcussive symptoms in children and adolescents. J Int Neuropsychol Soc. 2010;16(6):953-60. doi: 10.1017/S1355617710000986. [PubMed: 20735890].

24. Sojka P, Stalnacke BM, Bjornstig U, Karlsson K. One-year follow-up of patients with mild traumatic brain injury: occurrence of posttraumatic stress-related symptoms at follow-up and serum levels of cortisol, S-100B and neuron-specific enolase in acute phase. Brain Inj. 2006;20(6):613-20. doi: 10.1080/02699050600676982. [PubMed: 16754286].

25. Lin MR, Chiu WT, Chen YJ, Yu WY, Huang SJ, Tsai MD. Longitudinal changes in the health-related quality of life during the first year after traumatic brain injury. Arch Phys Med Rehabil. 2010;91(3):474-80. doi:10.1016/j.apmr.2009.10.031. [PubMed: 20298842].

26. Bryant RA, O'Donnell ML, Creamer M, McFarlane AC, Clark CR, Silove D. The psychiatric sequelae of traumatic injury. Am J Psychiatry. 2010;167(3):312-20. doi: 10.1176/appi.ajp.2009.09050617. [PubMed: 20048022]
27. Bryant RA, Harvey AG. Relationship between acute stress disorder and posttraumatic stress disorder following mild traumatic brain injury. Am J Psychiatry. 1998;155(5):625-9. doi: 10.1176/ajp.155.5.625. [PubMed: 9585713].

28. Polissar NL, Fay GC, Jaffe KM, Liao S, Martin KM, Shurtleff HA, et al Mild pediatric traumatic brain injury: adjusting significance levels for multiple comparisons. Brain Inj. 1994;8(3):249-63. [PubMed: 8004083].

29. Max JE, Schachar RJ, Landis J, Bigler ED, Wilde EA, Saunders AE, et al. Psychiatric disorders in children and adolescents in the first six months after mild traumatic brain injury. J Neuropsychiatry Clin Neurosci. 2013;25(3):187-97. doi: 10.1176/appi.neuropsych.12010011. [PubMed: 24026712].

30. Max JE, Pardo D, Hanten G, Schachar RJ, Saunders AE, Ewing-Cobbs L, et al. Psychiatric disorders in children and adolescents six-to-twelve months after mild traumatic brain injury. J Neuropsychiatry Clin Neurosci. 2013;25(4):272-82. doi: 10.1176/appi.neuropsych.12040078. [PubMed: 24247854].

31. Max JE, Keatley E, Wilde EA, Bigler ED, Levin HS, Schachar RJ, et al. Anxiety disorders in children and adolescents in the first six months after traumatic brain injury. J Neuropsychiatry Clin Neurosci. 2011;23(1):2939. doi:10.1176/appi.neuropsych.23.1.29. [PubMed: 21304136].

32. Andelic N, Jerstad T, Sigurdardottir S, Schanke AK, Sandvik L, Roe C. Effects of acute substance use and pre-injury substance abuse on traumatic brain injury severity in adults admitted to a trauma centre. J Trauma Manag Outcomes. 2010;4:6. doi: 10.1186/1752-2897-4-6. [PubMed: 20504353].

33. Anderson V, Godfrey C, Rosenfeld JV, Catroppa C. 10 years outcome from childhood traumatic brain injury. Int J Dev Neurosci. 2012;30(3):217-24. doi: 10.1016/j.ijdevneu.2011.09.008. [PubMed: 22100364].

34. Anderson VA, Catroppa C, Dudgeon P, Morse SA, Haritou F, Rosenfeld JV. Understanding predictors of functional recovery and outcome 30 months following early childhood head injury. Neuropsychology. 2006;20(1):42-57. doi: 10.1037/0894-4105.20.1.42. [PubMed:16460221].

35. Muscara F, Catroppa C, Anderson V. Social problem-solving skills as a mediator between executive function and long-term social outcome following paediatric traumatic brain injury.JNeuropsychol. 2008;2(Pt 2):445-61. [PubMed: 19824165].

36. Ponsford J, Willmott C, Rothwell A, Cameron P, Ayton G, Nelms R, et al. Cognitive and behavioral outcome following mild traumatic head injury in children.J Head Trauma Rehabil. 1999;14(4):360-72. [PubMed: 10407209].

37. Wrightson P, McGinn V, Gronwall D. Mild head injury in preschool children: evidence that it can be associated with a persisting cognitive defect. Journal of Neurology, Neurosurgery \& Psychiatry. 1995;59(4):375-80. doi: 10.1136/jnnp.59.4.375.

38. Jorge RE, Starkstein SE, Arndt S, Moser D, Crespo-Facorro B, Robinson RG. Alcohol misuse and mood disorders following traumatic brain injury. Arch Gen Psychiatry. 2005;62(7):742-9. doi: 10.1001/archpsyc.62.7.742. [PubMed:15997015]. 